\title{
UMA SOCIOLOGIA COMPREENSIVA SOBRE POLÍTICA E PANDEMIA NO BRASIL
}

\author{
George Fredman Santos Oliveira ${ }^{1}$ \\ Universidade Federal de Santa Catarina \\ georgefredoliveira@gmail.com \\ Alexandre Fernandez $\mathbf{V a z}^{2}$ \\ Universidade Federal de Santa Catarina \\ alexfvaz@uol.com.br
}

\begin{abstract}
Resumo
Este pequeno ensaio pretende refletir sobre as relações tensas entre o enfrentamento da pandemia do Covid-19 e a vida política no Brasil, abordadas em perspectiva constelar (figura presidencial, orla ministerial, séquito popular, poderes Judiciário e Legislativo, comunidade médica), verificadas na contumácia do presidente Jair Messias Bolsonaro para se manter no poder por dentro (ou a despeito) da pandemia contra a evidência dos registros de seus efeitos na saúde pública, arrevesando a política (lugar do poder) com o puro autoritarismo (lugar da violência). Os argumentos do ensaio percorrem as informações prestadas por diversos canais de comunicação no confronto entre objetividade-responsabilidade e as implicações éticas das/nas tomadas de posição política de um lado e da posição científica do outro.
\end{abstract}

Palavras-chave: COVID-19. Jair Messias Bolsonaro. Política Brasileira.

\section{A COMPREHENSIVE SOCIOLOGY ABOUT POLITICS AND PANDEMIC IN BRAZIL}

\begin{abstract}
This short essay intends to reflect on the strained relations between the fighting the Covid-19 pandemic and political life in Brazil. The approach is under a constellar perspective (presidential figure, ministerial border, popular entourage, Judiciary and Legislative powers, medical community), verified in the stubbornness of the president Jair Messias Bolsonaro. He remains in power inside (or despite) the pandemic against the evidence of the data of its effects on public health, mistaking politics (field of power) with pure authoritarianism (field of violence). The essay's arguments does a scan through the information provided by several media in the confrontation between objectivity-responsibility and the ethical implications of/in taking political positions on the one hand and scientific positions on the other.
\end{abstract}

Keywords: COVID-19. Jair Messias Bolsonaro. Politics Brazil.

\footnotetext{
${ }^{1}$ Doutorando em Educação pela Universidade Federal de Santa Catarina (UFSC). Mestre em Educação pela Universidade Federal de Santa Catarina (UFSC). Especialista em Gestão de Arquivos pela Universidade Federal de Santa Maria (UFSM). Graduado em Arquivologia pela Universidade Federal de Minas Gerais (UFMG). Graduado em Filosofia pela Pontifícia Universidade Católica de Minas Gerais (PUC/MINAS).

${ }^{2}$ Pesquisador CNPq 1C. Doutor em Ciências Humanas e Sociais (Dr. Phil.) pela Gottfried Wilhelm Leibniz Universität Hannover, Alemanha. Mestre em Educação pela Universidade Federal de Santa Catarina (UFSC). 


\section{ARTIGO}

INOVAÇÃo

\section{INTRODUÇÃO}

Pois no final das contas só há dois tipos de pecados mortais no campo da política: a falta de objetividade e - frequentemente, mas nem sempre idêntica a ela - a falta de responsabilidade (MAX WEBER, 2013).

A pequena epígrafe é do texto Política como vocação, de Max Weber, escrito no início do século XX. Essa reflexão, ao lado de outro texto do mesmo autor, Ciência como vocação, redigido na mesma época, está entre os textos ocidentais que conduzem a discussão da relação entre ciência e política, objetividade e ação, agente intelectual e agente político. Eles tratam de assuntos distintos, embora passem a ser costumeiramente mencionados como par depois de atingir um público maior de leitores na correnteza do tempo; contam em comum com o estilo e a erudição do seu autor, algumas citações e comparações que se repetem num e noutro, como as do texto bíblico e da mitologia grega, além das comparações entre casos da Alemanha, Estados Unidos, China, Índia, traço peculiar da produção weberiana.

Esse texto, como o seu autor foram lembrados neste microensaio em coocorrência ao “estado de coisas" que se enfrenta atualmente em relação à epidemia planetária no ano de 2020, em especial à performance social pela exposição à doença, particularmente o caso do Brasil, na singularidade histórica que atravessa.

A politização de um evento, assunto, pessoa não é uma situação nova na história, aliás não seria atrevido dizer que é tão antiga (ela, a politização) quanto os atos comunicativos entre os ancestrais da humanidade reunidos nos primeiros grupamentos dos quais se tem registro. Com a palavra (verbum- $\lambda o ́ \gamma o \varsigma$ ) nasce não apenas a possibilidade de se construir um mundo à imagem e semelhança do seu habitante humano, mas também a do exercício do poder, da dominação, algo mais: da incorporação da violência que até o advento da linguagem estava adstrita ao "estado selvagem" da "proto-humanidade".

Recolher uma reflexão consistente (se este for o melhor termo) em meio ao excesso informacional próprio do tempo em que se vive atualmente é a dificuldade que se impõe. Não é o caso de se fazer uma digressão sobre a sociedade da informação gestada nas últimas décadas; basta mencionar o seu impacto - diga-se de passagem: instrumental - em relação ao estado de coisas de que se participa no ano de 2020. A proximidade e o envolvimento individual e coletivo com a situação extrapola a constituição de um "modelo" razoável de compreensão do/no tempo corrente, obscurece a visão e o provimento de meios e mediações tanto do ponto de vista discursivo quanto pragmático para reagir e agir frente ao surto epidemiológico. A observação 


\section{ARTIGO}

INOVAÇÃo

imediata à esta última afirmação pode ser: mas há pessoas trabalhando, pensando e fazendo alguma coisa! Sim, e esta observação se baseia em uma objetividade!

Indicado o ponto de partida e situado o lugar histórico em que se insere, este pequeno ensaio pretende refletir sobre as relações tensas entre o enfrentamento da pandemia do Covid19 e a vida política no Brasil, abordadas numa perspectiva constelar (figura presidencial, orla ministerial, séquito popular, poderes Judiciário e Legislativo, comunidade médica), verificadas na luta insana do presidente Jair Messias Bolsonaro para se manter no poder por dentro (ou a despeito) da pandemia contra a evidência dos registros de seus efeitos na saúde pública, arrevesando a política (lugar do poder) com o puro autoritarismo (lugar da violência). Os argumentos do ensaio percorrem as informações prestadas por diversos canais de comunicação no confronto entre objetividade-responsabilidade e as implicações éticas das/nas tomadas de posição política de um lado e da posição científica do outro.

\section{PANDEMIA E CAMPO DO PODER: LÓGICA E DIALÉTICA DE UM CONFLITO POLÍTICO}

A epígrafe weberiana menciona um termo importante reivindicado pela vida administrada ocidental e, inclusive talvez, em parte, por esta razão, posta em "descrédito" pelas sociedades pós-críticas ${ }^{3}$, o termo em questão é objetividade.

Pois bem, o quanto das informações e tomadas de posição põem em relevância ou anulam a objetividade do Covid-19? Com os recursos das tecnologias e os motores de inferência e inteligência artificial ${ }^{4}$ é possível fazer estudos métricos, ou uma cientometria, da objetividade das afirmações e tomadas de posição em relação à epidemia planetária.

O excesso, em todo caso, é contrário à virtude. No caso do Brasil, não seria precipitado, ou mesmo desarrazoado afirmar que o atual mandatário do executivo federal comete os dois

\footnotetext{
${ }^{3} \mathrm{O}$ termo pós, além de ser uma armadilha terminológica, é uma armadilha hermenêutica, dado que tudo o que vier a acontecer depois que o leitor concluir a leitura da última palavra que fechar esta nota pode, com todas as razões, ser chamado de pós-texto. A reformulação do espaço e das relações sociais após as abordagens críticas da sociedade exigem a reformulação de diagnósticos, o produto é uma sociedade pós-crítica; pode não ser uma nova sociedade, pode, inclusive, ser uma sociedade regressiva instrumentalizada por novos aparatos técnicos de reprodução e dominação, o que significa, enfim, que tanto a sociedade quanto a crítica social são móveis mas não auto-anuláveis, pelo contrário, se uma época sonha a sua sucedânea (parafraseando Walter Benjamin) tanto o modelo de sociedade criticado quanto o diagnóstico crítico que lhe foi aplicado formam o par dialético para o qual o olhar do presente se volta e as obviedades se diluem quando não se está mais presente aos acontecimentos - é o presente que muda o passado, e não o contrário, e neste movimento o presente encontra o seu gérmen, ou o seu sonho plantado, o que torna possível, por exemplo, uma revolução citar outra.

${ }^{4}$ Conceito que em noutro momento pode ser discutido, qual outro tipo de inteligência conhecida que não seja artificial, ou até onde - excluindo-se as afirmações das tradições religiosas - se conhece uma inteligência natural, imanente à natureza, ou uma natureza naturalmente inteligente?
} 
pecados mortais weberianos (comete pecados não weberianos igualmente!). Para todo efeito, o comportamento do prócer é relevante, como relevante é o comportamento social diante da ocorrência pandêmica e o comportamento do "representante do povo" em relação ao comportamento do "povo". Não é segredo a postura anti-intelectual do presidente, e em boa dose não tem sido pudorosa a postura semelhante em parcelas de cidadãos brasileiros que se revestem da postura do seu representante, na ausência do decoro público a este substantivo se acrescentaria o prefixo im-postura ${ }^{5}$.

Mas voltando à "objetividade" sequestrada pela vida administrada contemporânea, sugere-se que se tome por certo que o Covid-19 é um existente, é um agente patológico, é altamente transmissível e está disseminado em todos os continentes no momento em que este texto está sendo escrito; tome-se que esta asserção não é a "opinião" dos autores deste texto, mas que as mortes resultado das contaminações são um "registro da realidade", como teria dito Lacan (2020), que informa esta objetividade. Caso não se conteste esta objetividade, atestada explicitamente na observação deixada para trás: de que há pessoas trabalhando, pensando e fazendo alguma coisa - porque estão, enfim, trabalhando, pensando e fazendo alguma coisa para combater uma doença e não uma ficção (ainda que existam ficções que merecessem ser combatidas) qual é ponto político alcançado por esta constatação?

A própria objetividade da constatação, na hipótese de que todos os seres humanos presentes à ocorrência da pandemia estejam persuadidos desta objetividade, seria o indício para as decisões e ações consequentes. Como se explica então, que mesmo os que estão convencidos dessa objetividade tomem a posição A e não a posição B em relação ao enfrentamento e os cuidados possíveis num cenário comportamental mais amplo? A resposta não é simples, mas uma simples resposta que pode ser dada nesta breve reflexão (o que não elimina ajustes e complementos), seria a de que o $a b$-uso político da situação se antecipou à objetividade requerida para uma ação política que correspondesse aos desafios trazidos para a coletividade pela pandemia.

“A doença não é uma metáfora", disse Susan Sontag (2002) há 40 anos, percorrendo em alguns exemplares dos textos literários do Ocidente a história da mistificação da doença e da condição do doente nesta sociedade. Elencando e descrevendo uma miríade de configurações metafóricas, Sontag aponta para a construção social da doença e do enfermo na significação de

\footnotetext{
${ }^{5}$ Nas palavras de Marcos Nobre (2020): "Bolsonaro encena ser um homem livre num país de confinados".

${ }^{6}$ Walter Benjamin (1984, p. 188) fórmula na Origem do drama barroco alemão esta constatação da seguinte forma: "quanto maior a significação, tanto maior a sujeição à morte, porque é a morte que grava mais profundamente a tortuosa linha de demarcação entre a physis e a significação".
} 


\section{ARTIGO}

INOVAÇÃo

imaginário. Sem pretender recusar à literatura (ou exigir que se recuse a si mesma na sua condição de expressão artística) sua liberdade comunicativa de se auto-representar e representar o mundo ${ }^{7}$, chama-se a atenção para a inversão hermenêutica trazida para o plano social, ao que Safatle (2004) traduziu (remetendo-se a Lacan) como literalização da metáfora, na qual este índice do registro da realidade (a metáfora) toma o lugar da experiência dentro da realidade que se experimenta, para a qual caminha a reflexão de Sontag: não se pode esperar que o corpo adoecido lide com a doença que o acomete como se esta fosse uma ficção (produto da imaginação), ou o contrário: conferir ao conjunto de imagens dispostas na construção social a hipóstase da consciência coletiva o imperativo para a conduta.

Quando a Literatura, a Filosofia, o Direito, ou a experiência estética, de uma maneira geral, utilizam o índice metafórico para descrever (quando não, explicar) a experiência mundana por esta figura linguística, operam por dois recursos disponíveis entre os artefatos humanos: mediação e mímesis. Quer dizer, a linguagem é o simulacro da experiência e da vida social; alegorias, metáforas, ironias, paródias são as formas plásticas assumidas pelo enunciado. A emulação da linguagem prescreve as suas próprias regras, veja-se os jogos de linguagem de Wittgenstein, por exemplo. A plasticidade que ab-roga passa menos por fora que intrinsecamente às relações humanas, porque, mesmo na constituição do solilóquio intrassubjetivo, as condições do enunciado foram oferecidas pela formação do enunciador para que ele (o solilóquio) se efetive, ou seja, a gênese do monólogo privado subjetivo é pública, inclusive, e proporcional ao repertório das formas plásticas à disposição ${ }^{8}$. As formas do enunciado não são uma criação ex nihilo do indivíduo-sujeito, senão que postos em ação seja no solilóquio ou no colóquio.

Com a devida vênia às figuras de linguagem, muito pertinentes e necessárias por sinal, utilizadas pelos mais diversos enunciadores nos mais diversos púlpitos: as metáforas, parábolas, analogias, homologias - sociedade virulenta; as máscaras das personas, vírus da globalização, e quantas mais a inteligência e criatividade humana dão conta de pronunciar, no Brasil está-se a mobilizar (ou numa palavra mais dura: manobrar) as disposições sociais na direção do

\footnotetext{
${ }^{7}$ Quando a tradição estética, ou estética tradicional, afirma a arte como a elevação do homem, menos que princípio moral (ou categórico na formulação kantiana), afirma-se, outrossim que na arte não há elevação, senão que ao celebrar o humano, desce à estatura deste humano; a elevação da arte, nesta diálise, seria o seu rebaixamento, por fim, porque se afirma imagem e semelhança humana paralisada no limite desta estatura e todo suposto avanço se resume à equiparação pari passu do que é o humano em cada instantâneo do histórico.

${ }^{8}$ Papel reservado à transmissão da cultura, realizado por iniciação (momento filogenético) e sustentado na socialização (momento ontogenético). Ao contrário do que pensa movimento do senso comum não é o neófito apresentado ao mundo pela linguagem, mas o contrário: é a linguagem que introduz este candidato à humanidade no mundo construído nela e por ela (a linguagem): está no mundo (historicamente e socialmente inserido) quem aprendeu a decodificar o livro do mundo.
} 
desgaste político em lugar da condução responsável para o enfrentamento da pandemia e de suas consequências.

Que fique claro o que está sendo afirmado nestas páginas: não é uma mera acusação de manipulação social, é algo graus mais grave: é o esgotamento deliberado do diálogo na esfera pública para que toda e qualquer conduta cujo adjetivo seja democrático caia em total descrédito social. Algo que se viu ensaiado na última campanha eleitoral e que neste momento está sendo levado às últimas consequências apoiando-se no dissenso em torno da questão epidemiológica.

Recorrendo-se novamente aos textos de Weber, três apontamentos são importantes frente ao atual cenário: a relação da liderança e do estamento que serve ao governo ou governante, ao que Bourdieu $(1983 ; 2011)$ posteriormente denominará de campo do poder; o monopólio legitimado da violência (física e simbólica) e a ética (da convicção e da responsabilidade).

Sob o pretexto da contenda entre o diagnóstico e profilaxia indicada pela medicina e as decisões políticas que envolvem as tomadas de posição em relação à pandemia, no caso do Brasil encena-se o encaminhamento da apropriação do poder para o qual o palco estava montado antes da crise pública de saúde que se instalou. Eis o que está em jogo no país: não é a condução das forças sociais e políticas coordenadas num esforço de compreensão e enfrentamento do registro de realidade desencadeado pelo Covid-19. Tem-se duas objetividades em disputa no momento: a objetividade trazida à tona pela epidemia planetária e a objetividade das relações do campo do poder representadas na performance dos dirigentes e executores políticos que insuflam na sociedade setores cooptados para que consintam no uso de estratégias reconhecidas de violência num passado não muito distante, repudiando toda base ética ou bioética (em tempos de discussão biopolítica) disponível no presente.

Entre a sucessão de eventos, declarações e aparições públicas da figura presidencial estão as evasões de ministros: o primeiro, o ex-juiz Sérgio Moro, que pode ser considerada a maior perda política do mandato presidencial instalado em 2019; afirma-se isto porque a imagem mitificada do ex-magistrado assume um conflito frontal com a imagem mitificada do ex-militar chegando às "vias judiciais de fato" pela abertura do inquérito no Supremo Tribunal Federal no qual é investigada a possível ingerência do presidente sobre a organização da Polícia Federal, especialmente no estado do Rio de Janeiro, onde há outras investigações em andamento envolvendo familiares e pessoas que lhe são próximas; o segundo, Luiz Henrique Mandetta, em notório desacordo com a postura do seu "chefe" em relação às proposições da pasta para o enfrentamento da pandemia; o terceiro, Nelson Teich, com passagem brevíssima pela função 
ministerial, ambos deixam o Ministério da Saúde no momento em que os dados da dispersão do Covid-19 sobem a curva no Brasil.

As duas pontas ministeriais ilustram como a evasão dos spearheads do estamento do Executivo Federal comunicam essas objetividades em disputa no cenário que este ensaio procura refletir: uma diz respeito às prováveis fontes de ameaça que a figura presidencial sente sobre si incorporadas nas instituições do Congresso Nacional e no Superior Tribunal Federal (ameaça esta materializada no inquérito, que se convertido em processo por crime de responsabilidade poderá custar-lhe o posto presidencial), não casualmente as duas instituições sob ataque na panfletagem dos simpatizantes bolsonaristas que estão boicotando as recomendações do afastamento social nas manifestações das ruas; recomendações estas avalizadas pelos médicos (segunda objetividade) que estiveram à frente do Ministério da Saúde, as mesmas recomendações (fazem crer as informações vindas a público em muitos canais de comunicação, e das próprias declarações dos ministros demissionários), que lhes custaram as funções ministeriais.

Os desditos recorrentes da figura presidencial são outro exemplo da corrosão semiológica a que encaminha os governados, como quando se auto-afirma a Constituição enquanto "rememora" o golpe civil-militar de 1964 no dia 31 de março. Não se trata de uma mera contradição de princípios, ou de uma esquizofrenia (falta de interação com o mundo exterior), em qualquer ocasião o que presidente pretende exibir é a própria auto-exibição; re(co)memorar o evento que dissolveu as instituições democráticas e as prerrogativas civis protegidas pela atual Constituição Federal assumindo uma identificação personalizada com a própria Constituição de forma alguma indica, na lógica do seu enunciador, um erro de agente, como diria Austin. Nas duas situações (a comemoração do golpe de 1964 e a autoproclamação em homo constituicionis) revela-se expressão daquilo há pouco descrito: literalização, o índice do registro assume os topos da experiência na realidade que se experimenta e o conjunto das imagens à disposição são hipostasiadas na/pela consciência.

A crise interna entre o chefe do executivo e os seus "subordinados" têm ocupado o primeiro plano da cena pública nacional. Enquanto o presidente "perde o controle" da primeira leva de arregimentados e debate-se em recrutar novos colaboradores entre as fileiras dos alinhados mais empedernidos à sua "visão de mundo gerencial", aposta na alternativa do “corpo-a-corpo" - numa clara recorrência à tática executada na campanha eleitoral -, tentativa desesperada de demonstração de "interesse pelas causas levadas à rua" nos recentes movimentos verde-amarelo anteriores à eleição, que às querelas palacianas em Brasília. 
A tática do corpo-a-corpo é insistentemente repetida em desacordo à recomendação da comunidade especializada da medicina: corpo-não-toca-corpo no território da pandemia. A expectativa de que a imagem do presidente fora do Palácio da Alvorada (porque edifícios públicos no Brasil, quer sejam para moradia ou trabalho continuam a serem nomeados palácios, mesmo após a queda da monarquia, ainda não se explica - ou quando se explica, não se justifica), nas ruas sob o risco de contaminação e disseminação da doença provocaria uma reação negativa da população é devolvida pelos setores mais fascinados (encantados pelo carisma) pelo líder com o qual se identificam no padrão da aquiescência. O investimento na contramão do corpo-não-toca-corpo, neste caso, faz sentido (na estratégia da figura presidencial): é a afirmação do eleito para os seus eleitores - eu estou com vocês, tragam-me as suas pautas! Como o sino de Pavlov havia sido tocado antes, durante o período da campanha eleitoral, fica previsível reconhecer quem estaria nas ruas e quais pautas seriam levadas, estampadas nas faixas e cartazes clamando por intervenção militar, dissolução do Congresso Nacional e do Superior Tribunal Federal.

A desconfiança de algumas figuras entre os colaboradores do escalão palaciano no círculo mais fechado do Executivo Federal empurra o presidente a procurar nas ruas apoio, apoio este fragilizado nas relações político-administrativas que necessitam, pelas características burocráticas instaladas na administração pública brasileira desde o primeiro Governo Vargas, de uma camada - mínima que seja - de negociação, diálogo e sujeição a alguns protocolos.

Desta forma, para a manutenção do posto presidencial, a auto exposição e a exposição de seus eleitores ao risco de contaminação pelo Covid-19 é o menor dos males. A legitimação do monopólio da violência advogada nas ruas: a consagração do líder que está disposto a todo e qualquer sacrifício para realizar o desejo do povo, povo este também disposto ao menor dos males (pelo menos os que continuam indo às manifestações na rua).

E como uma coisa uma leva à outra? Numa simplificação: com uma única solução duas crises são mitigadas: a crise pública de saúde e a crise da manutenção do poder. A questão epidemiológica deixa de ser uma questão no cenário em que for aplicado o uso autocrático do monopólio da violência sobre os poderes republicamos, neste caso ter-se-ia a substituição do isolamento-confinamento-distanciamento social recomendando com fundamento na expertise médico-sanitária pelo estado de exceção propriamente dito conhecido na literatura jurídicopolítica. O que de certa forma tornaria mais distinta cada coisa para aqueles que absorvem o primeiro (a crise de saúde pública politizada) no segundo (o golpe da cúpula do Executivo sobre os demais poderes republicanos). 
Como antecipado há pouco, são postas à prova as condições éticas que poderiam dar anteparo tanto à situação da saúde coletiva como à manutenção do estatuto democrático abrogado pelo Estado brasileiro. Não se diz com isto que uma tipologia ética está subordinada à outra. Constata-se, outrossim, que a comunidade médica, com as atualizações que isto demanda, age sob a ética hipocrática, ontogeneticamente a bioética ocidental, e sob este imperativo recomenda o "isolamento" do doente (seja ele um indivíduo, seja ele a sociedade). Ela (a bioética) pode ser sacrificada para que o exercício do monopólio da violência triunfe, como planejado pelo autocrata, nas suas mãos: o sacrifício por meio do mal menor, explicado pela tática do corpo-a-corpo e pela estratégia do ataque à forma democrático-republicana.

A sujeição e o controle dos corpos e da vida reclamada pela biopolítica, neste caso, está num plano secundário em relação à proeminência do conflito entre a bioética e o extremismo antidemocrático. Ou melhor, há uma elisão dos temas da bioética e da biopolítica na dinâmica da figura presidencial, a sua pauta emergencial é outra. Remete-se, em relação a isso, à posição do filósofo Giorgio Agamben a respeito da pandemia como dispositivo.

Se Agamben (2020) se equivoca ao afirmar que a epidemia é uma invenção, não é o caso quando também afirma que a violência pode ser exercida pelo Estado numa circunstância em que o pânico e o medo coletivos sejam mobilizados com este fim. Virtualmente, o autocrata pode usar qualquer pretexto para violentar institucionalmente os governados, inclusive uma pandemia, mas isto não a transforma necessariamente numa ficção. As premissas e as conclusões que formula, talvez careçam de mediações, e por isto estejam tão distantes umas das outras na discussão que propõe sobre a epidemia planetária.

No trato tradicional que se dá ao estado de exceção, as formas consagradas no Direito Ocidental, em que, pouco se duvida, sobressai um mal elaborado juspositivismo, a suspensão da "normalidade" das relações sócio-jurídicas são confiscadas pelo autocrata e o pano de fundo se resume à oposição binária direitos $\mathrm{X}$ não-direitos obnubilada no estado de anomia deflagrado pela calamidade-desastre-emergência, a máxima benjaminiana: "a tradição dos oprimidos nos ensina que o estado de emergência no qual vivemos não é uma exceção, e sim uma regra" (BENJAMIN, 2013, p. 10) não penetra o problema com a profundidade que este dístico pode alcançar, presumido por Agamben.

O estado-de-exceção perpétuo que historicamente subjuga os corpos dos oprimidos não autoriza a Agamben ou ao presidente do Brasil (aqui se tergiversa sobre a possibilidade deste último mencionar Agamben ou Benjamin!) presumirem que a pandemia é uma invenção, atitude que poderia ser considerada, no mais das vezes, similar à literalização da metáfora. Para os que sub-existem em contínuo estado de exceção a pandemia que não estiver sob o controle 
de medidas de contenção sanitária é sua sentença de morte, o que, salvo engano, não se constitui o propósito de um Estado e sociedades ditas livres e democráticas: deliberadamente condenar a população empobrecida à morte, porque nesta condição de empobrecimento estão mais vulneráveis às doenças - sejam ou não essas vidas nuas; é aqui que reside o paradoxo da reflexão de Agamben: o potencial que as medidas de isolamento-distanciamento social possuem para controlar os corpos (biopolítica) na ocorrência da pandemia (a favor de todas as probabilidades disto vir a ocorrer) é simetricamente proporcional ao potencial que tais medidas têm para proteger os oprimidos da tragédia social que a negligência destas mesmas medidas pode provocar. Ou num resumo direto: a liberdade individual advogada no argumento de Agamben, no qual, torna-se violência nas mãos do autocrata, e o estado de exceção que pretende denunciar não se anula na intervenção do Estado, mas pela inversão do argumento usado, enfim, contra qualquer liberdade.

Contra a prédica tradicional, levada a termo pelo juspositivismo, de que contra fatos não há argumentos, este ensaio problematiza os eventos que dizem respeito à performance política e à pandemia que se entrelaçam nos enunciados públicos como registros de realidade aos quais pretende depurar das literalidades com as quais se comprometem as objetividades postas em movimento pelos agentes por trás dos enunciados: objetividades que comunicam objetivosprojetos.

Objeto-objetividade-objetivos se decompõem-recompõem, por fim, na ação social propriamente dita: numa em que o agente tenta salvar sua posição no campo do poder e numa em que os agentes tentam preservar corpos e vidas (nus e nuas). Na primeira revela-se a repetição, contumácia, e recorrência aos slogans instalados na experiência ditatorial do passado recente do Brasil. Na segunda revela-se a récipe orientada pela terapêutica aplicável à doença sob a roupagem de um código de posturas globalizado (lavar as mãos, usar máscara, distanciarse), que, sim, alcançados pelo poder de polícia do Estado convertem-se em biopolítica, que por sua vez penetrando nos costumes assumem-se em novo processo civilizador.

É legítimo que se interpele neste ponto: afinal, de onde surgiu esta nova objetividade em discussão, o que torna esta objetividade objetiva? O argumento da autoridade weberiana? Como reclamar objetividade sobre estatutos tão distintos quanto ao registro de realidade sobre os quais se assentam? Todo este excurso se propõe a conduzir o leitor a um engodo, um argumento paralógico, lançar-se-á mão das figuras de linguagem deixadas há pouco para trás?

Um lógico responderia que a objetividade é uma propriedade do objeto (ao conceito objeto esta propriedade é imanente) e não do sujeito, um dialético responderia: em sendo objetivo que o vírus Covid-19 é um existente, é um agente patológico, é altamente transmissível

P2P \& INOVAÇÃO, Rio de Janeiro, v. 7, Ed. Especial, p. 86-100, set. 2020/fev. 2021. 
e está disseminado em todos os continentes neste momento, sendo estas suas propriedades o estatuto da sua objetividade; igualmente pode-se afirmar tomando-se as propriedades estatutárias da objetividade que: nas últimas aparições do mandatário do executivo federal (performance no campo do poder), este senhor endossou com tais aparições práticas contrárias à forma democrático-republicana do Estado brasileiro, como a dissolução do parlamento nacional, restrição às atividades jurisdicionais e o aval a dispositivos de repressão de governos autoritários passados, como o AI5 (estratégias reconhecidas de violência); e que a performance adjudicatária à tais estratégias está em conflito com a ética esperada de um chefe de estado (inclui-se aí a bioética, face às recomendações da comunidade médica para que se evite aglomerações).

O leitor retorquiria: mas sobre as informações prestadas no último raciocínio não há consenso ou relação causal em que uma ação leva à outra. $\mathrm{O}$ dialético poderia então replicar: se o novo estatuto da objetividade reclamada for o consenso, façamos novamente o caminho percorrido sobre este novo estatuto e testemos em que pesa a objetividade de o Covid-19 ser um existente... e o campo do poder que busca ressuscitar velhas estratégias de violência institucionais incorporadas no atual governante serem mais ou menos consensuais e em que planos sociais sejam mais ou menos consensuais.

Frente às estratégias utilizadas para a enunciação das justificativas para uma ou outra objetividade, uma ou outra tomada de posição, a tarefa que se impõe ao corpo social afetado ao mesmo tempo pela pandemia e pela contumácia política do presidente é a de examinar em que planos sociais os consensos proferidos dizem respeito às necessidades instaladas por cada situação. Por exemplo: qual é a necessidade social premente neste momento no país, uma política pública de saúde para combater o Coronavírus ou a dissolução dos poderes Judiciário e Legislativo? Posta desta forma, a pergunta talvez deixe mais clara a diferença do que é uma necessidade social e o consenso a este respeito, e o que é desnecessário (criminoso, na verdade!) e sobre o que (uma inconstitucionalidade) este consenso repousa. A resposta a esta pergunta também ajuda a identificar os atores sociais que sustentam cada consenso e quais objetivos pretendem atingir com tal consenso, mostrando a potência de cada lado do discurso; a potência fixada (a que diz respeito aos recursos empregados, a legitimidade destes recursos, e escala de alcance) e a potência performática (a que diz respeito à capacidade de persuasão, pactuação, ajuste, reconstrução da estabilidade sociais - mínimos que sejam).

Contra o argumento que poderia se levantar de que se trata de registros extremamente distintos de afirmações: a objetividade da epidemia planetária, e a objetividade das táticas e estratégias da figura presidencial em direção à tomada do monopólio da violência contra a 
forma democrático-republicana do Estado brasileiro, uma boa réplica seria então a opção de se deixar em suspenso o sentenciamento lógico e sopesar a valoração das objetividades postas à prova neste ensaio.

Para que esta valoração não prejudique nenhuma das duas objetividades, tal valoração deve ser medida por pressupostos não excludentes, substantivos, socialmente e juridicamente reconhecidos, que possam ser invocados por qualquer cidadão brasileiro e não sejam a mera opinião dos autores deste ensaio: as garantias constitucionais à saúde e à vida, e aos Poderes da União.

Neste terreno, o das garantias constitucionais, a discussão migra das elipses se a proteção à saúde e vida, ou a legitimidade e independência dos Poderes Republicanos são mais ou menos objetivos, porque, em todos os casos, são esses temas professados como valores constitucionais e públicos. Poderia se redarguir que na falta de opções os ensaístas apelaram para o argumento constitucional, e que tais regras (as da Constituição Federal) são demasiado genéricas, carecem de interpretação e de outros instrumentos que as tornem exequíveis.

Genéricas, sujeitas à hermenêutica e carentes de instrumentos executórios, ainda assim são pressupostos não excludentes, substantivos, socialmente e juridicamente reconhecidos, podem ser invocados por qualquer cidadão brasileiro e não são mera opinião dos autores deste ensaio. Os limites das garantias constitucionais não as tornam escusáveis, não diminui seu caráter de matriz para a agência pública do Estado e da sociedade seja em tempos de pandemia, seja em tempos de crise econômica ou em tempos de saúde e abundância. Neste sentindo a recorrência ao argumento constitucional não se constitui uma fuga apelativa, mas um índice de racionalidade e razoabilidade disponíveis e socialmente significativos quando se trata das ações políticas às quais o chefe do executivo federal in propositum e in actum responderia na condição de mandatário presidencial.

Obviamente valores sociais só o são (valores) na medida em que nesta qualidade são construídos e experimentados por aqueles que participam da cultura que os nomeia. Neste ponto pesa a pergunta: está o ordenado (aquele que recebeu as ordens, o múnus) político respondendo à objetividade e à responsabilidade juramentada no protocolo do compromisso constitucional no ato da posse presidencial: "manter, defender e cumprir a Constituição, observar as leis, promover o bem geral do povo brasileiro, sustentar a união, a integridade e a independência do Brasil”? Não seria tal juramento o código deontológico (código de ética) presidencial?

Longe de transformar este exercício numa interminável estrada de argumentos e contraargumentos o intento central deste texto é chamar a atenção para a objetividade e a responsabilidade que está em jogo no atual cenário, considerando o índice do registro de 
realidade que pesa sobre mandatários, leaders e governados. Afinal quais e quantos brasileiros estão dispostos a sacrificar os seus em nome do nobre e cristão princípio do mal menor?

\section{3 À GUISA DE UMA CONCLUSÃO}

Seguindo uma tradição weberiana, este microensaio tentou, por fim, atualizar uma sociologia compreensiva no tempo presente (o ano de 2020) na qual os termos/categorias objetividade e responsabilidade são confrontados com a performance política da figura presidencial no cenário da epidemia planetária do Covid-19. A convicção assumida sugere que há um divórcio proposital entre a tomada de posição do presidente da república e a tomada de posição da comunidade científica representada pelos profissionais da área de saúde. No caso, o mandatário abre mão do binômio weberiano (objetividade-responsabilidade) pelo distanciamento e pela tentativa de solucionar um conflito político subterrâneo particular: a deslegitimação relativa da sua figura presidencial nos meandros palacianos valendo-se da tática do corpo-a-corpo utilizada nos tempos da campanha eleitoral em oposição à recomendação médico-sanitária corpo-não-toca-corpo na ocorrência da pandemia. Para fazer este exercício, utilizou-se das figuras lógicas e dialéticas para pôr à prova a objetividade da tese sugerida, como também de um pressuposto valorativo que sopesasse a sustentação da tese de maneira equânime e insuspeitável para o leitor. As garantias constitucionais foram pressupostas escolhidas que, como visto na conclusão do argumento de valor, pesam sobre a instituição presidencial como seu "código deontológico". Durante o excurso do microensaio foram arrolados vários índices que transitam entre o formalismos lógico-jurídicos e sócio-empíricos (como as aparições do presidente nas manifestações anti-poderes democrático-republicanos), para demonstrar a objetividade da própria argumentação e de como há o deslocamento da atenção política sobre a saúde pública para a manutenção do status do poder presidencial do ocupante da função que, ameaçado, está disposto a lançar mão do uso da violência para não ser destituído do campo do poder. 


\section{REFERÊNCIAS}

BENITES, Afonso; BETIM, Felipe. Bolsonaro rompe isolamento e vai a atos contra o Congresso em meio à crise do coronavírus. El Pais, 15 mar., 2020. Disponível em: https://bra sil.elpais.com/brasil/2020-03-15/bolsonaro-rompe-isolamento-e-endossa-atos-contracongresso-em-meio-a-crise-do-coronavirus.html. Acesso em: 13 maio 2020.

BARROS, Marcelo Vinícius Miranda. Bolsonaro ao dizer "eu sou a Constituição", assume um erro filosófico e psicológico. Jornal GGN, 06 maio, 2020. Disponível em: https://jornalg gn.com.br/artigos/bolsonaro-ao-dizer-eu-sou-a-constituicao-assume-um-erro-filosofico-epsicologico-por-marcelo-v-miranda-barros/. Acesso em 24 maio 2020.

BENJAMIN, Walter. O anjo da história. Autêntica, 2013.

BENJAMIN, Walter. Origem do drama barroco alemão. São Paulo: Brasiliense, 1984.

BOURDIEU, Pierre. Campo de poder, campo intelectual. Buenos Aires: Folios, 1983

BOURDIEU, Pierre. O campo político. Revista Brasileira de Ciência Política, n. 5, p. 193-216, 2011. Disponível em: http://www.scielo.br/scielo.php?pid=S0103-335220110001 00008\&script=sci_arttext. Acesso em: 24 maio 2020.

CHAVES, Wilson Camilo. O estatuto do real em Lacan: dos primeiros escritos ao seminário VII, a ética da psicanálise. Paidéia, Ribeirão Preto/SP, v. 16, n. 34, p. 161-168, 2006.

Disponível em: https://www.scielo.br/pdf/paideia/v16n34/v16n34a04.pdf. Acesso em: 13 maio 2020.

COLON, Leandro. Moro pede demissão após troca na PF, e Bolsonaro tenta reverter. Folha de São Paulo, 23 abr. 2020. Disponível em: https://www1.folha.uol.com.br/poder/2020/04/bo lsonaro-avisa-moro-que-vai-trocar-diretor-geral-da-policia-federal.shtml. Acesso em: 13 maio 2020.

CORONAVÍRUS: a OMS declara pandemia. BBC News Brasil, 11 de março de 2020. Disponível em: https://www.bbc.com/portuguese/geral-51842518. Acesso em: 13 maio 2020.

ELIAS, Norbert. O processo civilizador: uma história dos costumes. Rio de Janeiro: Jorge Zahar Ed., 1994, v I.

ELIAS, Norbert. O processo civilizador: formação do Estado e Civilização. Rio de Janeiro: Jorge Zahar Ed., 1993, v. II.

AGAMBEN, Giorgio. Estado de exceção: [Homo Sacer, II, I]. Rio de Janeiro: Boitempo Editorial, 2015.

AGAMBEN, Giorgio. La invencion de una epidemia. In. AGAMBEN, Giorgio et al. Sopa de Wuhan. ASPO (Aislamiento Social Preventivo y Obligatorio), 2020. p. 17-19.

GLOSSÁRIO DE LACANÊS. 2020. Disponível em: https://www1.folha.uol.com.br/fsp/mais/ fs0804200106.htm. Acesso em: 13 maio 2020.

GODOY, Arnaldo Sampaio de Moraes. Estado de exceção e anormalidade constitucional no contexto da CF. In. Boletim de Notícias do CONJUR, 29 mar. 2020. Disponível em: 
https://www.conjur.com.br/2020-mar-29/embargos-culturais-estado-excecao-anormalidadeconstitucional. Acesso em: 24 maio 2020.

MORI, Letícia. Como ordem de Bolsonaro para comemorar golpe de 1964 se transformou em problema para as Forças Armadas. BBC NEWS, 29 mar. 2019. Acesso em: https://www.bbc. com/portuguese/brasil-47741593. Acesso em: 24 maio 2020.

NOBRE, Marcos. Marcos Nobre ao EL PAÍS: "Bolsonaro tenta destruir as instituições por dentro". Professor da UNICAMP e presidente do Centro Brasileiro de Análise e Planejamento (CEBRAP) conversou sobre a crise no Governo Bolsonaro. Entrevista faz parte de série multiplataforma do jornal. EL PAIS, 04 jun. 2020. Disponível em: https://brasil.elpais.com/br asil/2020-06-03/el-pais-entrevista-ao-vivo-o-filosofo-marcos-nobre-nesta-quinta-feira.html. Acesso em: 04 jun. 2020.

SAFATLE, Vladimir. Estética do real: pulsão e sublimação na reflexão lacaniana sobre as artes. O tempo, o objeto e o avesso: ensaios de filosofia e psicanálise. Belo Horizonte: Autêntica, p. 116-117, 2004.

SIMANKE, Richard Theisen. A letra e o sentido de "retorno a Freud' de Lacan: a teoria como metáfora. In: SAFATLE, Vladimir (org.). Um limite tenso: Lacan entre a filosofia e a psicanálise. UNESP, 2003. p. 277-303.

SONTAG, Susan. A doença como metáfora. Rio de Janeiro: Graal, 2002.

WEBER, Max. Política como vocação. In: BOTELHO, André (org.). Essencial Sociologia. São Paulo: Companhia das Letras, 2013. p. 153-176.

WEBER, Max. Ciência como vocação. In: BOTELHO, André (org.). Essencial Sociologia. São Paulo: Companhia das Letras, 2013. p. 140-151. 